\title{
Contextual Challenges in Using DERs to Advance Remote Electrification
}

\author{
Abhiroop Chattopadhyay \\ Electrical and Computer Engineering, \\ University of Illinois \\ at Urbana-Champaign \\ ac33@illinois.edu
}

\author{
Ann-Perry Witmer \\ Applied Research Institute \\ University of Illinois \\ at Urbana-Champaign \\ awitmer@illinois.edu
}

\author{
Peter W. Sauer \\ Electrical and Computer Engineering, \\ University of Illinois \\ at Urbana-Champaign \\ psauer@illinois.edu
}

\begin{abstract}
This paper describes some non-technical challenges of utilizing Distributed Energy Resources (DERs) to achieve electrification in remote rural regions that fall outside the reach of the conventional utility grid. These non-technical challenges stem partly from the inability to utilize economies of scale, but are also related to place-based contexts of the communities that these systems are designed to serve. This paper provides some insights from a case study of DER usage for electrification in the Navajo Nation (NN) and the challenges that are involved. It describes through this illustrative case study why technology solutions and long-term policy initiatives and support - explicitly crafted using knowledge of place and people - are necessary to advance electrification goals in rural and under-served communities.
\end{abstract}

\section{Introduction}

Electrification is increasingly becoming the backbone of the modern era, with electricity fast becoming the primary form in which we consume energy. Nonetheless, for nearly 1 billion people on Earth, a disproportionate number of whom are in rural, under-served communities, unreliable access to (or complete lack of) energy remains a chronic problem, a phenomenon referred to as energy poverty [1]. Reducing this energy poverty by improving access to energy has significant capacity to improve various aspects of the human condition, including communication and education [2], as well as health [3]. Generating and providing reliable energy at the scale required to reach these communities will likely be a massive undertaking in itself. The imminent climate crisis only exacerbates this challenge, as we must find a way to generate this energy while also aggressively minimizing our carbon footprint from point and non-point emission sources. As such, the goal of energy poverty reduction can be realistically realized without long-term negative consequences only if it is achieved using energy sources that do not produce carbon emissions, such as renewable resources of wind and sun [4]. A major hurdle which remains in the pursuit of this goal is the cost associated with last mile electrification, which remains prohibitive in many places, particularly in sparsely populated rural regions of the world. Distributed Energy Resource (DER) systems, utilizing solar photovoltaic (PV) and wind energy resources, are a technology platform that have the potential to help us overcome the last mile hurdle, realize electrification objectives, while also minimizing our carbon footprint.

DER systems that are deployed to sparsely populated rural or remote locations may vary in installed size and specifics, but they all do share a few salient features. These systems are typically not connected to a larger bulk power grid, and they are powered primarily by renewable energy such as PV or wind. (Some systems may include fossil fuel-based backup for greater reliability, but we focus our attention on the DER systems powered using renewable energy only). These systems also tend to not be excessively complex from the technical standpoint. These DER systems may be broadly categorized into network-type microgrid systems or standalone solar home systems (SHS). The system-level designs of such DER systems are well-established, and they are typically built using commodity components such as inverters, solar PV panels, and batteries which are manufactured at scale. As manufacturing methods of the components have improved/matured, improving reliability and efficiency and reducing manufacturing costs, the promise and scope of applicability of these DER systems has widened. However, in real life instances, the potential of these systems has often not been realized to their fullest extent. Follow-up studies of systems deployed in the field find that the success of these systems are far from assured, with many under-performing, in various states of disrepair, or completely moribund [5], [6]. There is a greater need to understand why certain systems do not gain acceptance in specific contexts [7]. 


\section{The Importance of Context of Place and People}

Insufficient strategic thought has been given to developing concerted policy-driven approaches to the deployment and use of DER systems to aid in low-cost electricity access in remote rural regions that lie outside the reach of the traditional electric grid. This is particularly acute in sparsely populated rural regions wherein the consumer market does not have the market influence that incentivizes commercial entities to devote resources for electrification. A variety of non-governmental organizations have stepped in to fill this vacuum. The background of these organizations is varied, including outreach wings of professional organizations, project-based student learning organizations, evangelical organizations, and nondenominational service organizations. These different entities, all with distinct operating paradigms, objectives, and metrics of success [8], have produced a very fragmented landscape as far as DER system deployments are concerned. As a result of this piecemeal approach, the ultimate outcomes of DER system projects have been highly variable, with the vast majority not lasting anywhere near their designed lifetimes [6]. The true extent of failure is notoriously hard to determine, as these DER systems are installed by a variety of entities with correspondingly different notions of success. Failure rates are poorly documented, and tend to be approximated. Though accurate statistics on the failure rate of rural renewable energy systems does not readily appear in the literature, anecdotal evidence indicates failure rates of as high as $90 \%$ in some cases [6]. (The same author conducted an informal survey in Mauritania, West Africa, and found that $100 \%$ of wind-electric turbine systems for pumping water were non-functional at the time of visit). These failure rates were reported for systems provided by pro-bono humanitarian or philanthropic agencies, which typically do not possess the logistical resources to provide continued support for developed energy projects. These projects are typically designed and developed with the intention of being handed over to the recipient community, with the expectation that the community will develop a working strategy to maintain these projects. Even in instances where DER systems are deployed based on strategic road maps set by governments, systems reported as functional are often found to have failed to meet their users' original expectations. In one instance, the authors of this paper were informed of several failed DER systems in a province of a Southeast Asian country. The systems were provided by a variety of entities under a government-developed microgrid deployment road map. Subsequent follow-up in the field found that many of the systems ultimately failed, with the failure period being reported to be anywhere from within a month to about five years.

While the intricacies of failure of such systems are complex, one thing is very clear: these failures are not so much due to technical issues with the DER systems, as to a lack of consideration of the non-technical aspects of the communities for whom these systems were built [9]. It is important to understand that social aspects are equally relevant for success [10].

Rural societies display their own set of unique challenges when it comes to design of engineered energy systems, many of which are non-technical [11]. To understand these communities and the paradigms within which they interact with an external technology, one must understand not only the people- and place-based contextual aspects at the time of observation, but also other factors that have resulted in the situation that they find themselves in at the time of observation. These include the global influences, such as historical conditions and broad identity issues (eg, marginalization of minority populations); local conditions, such as geographical proximity to agricultural markets, soil conditions, resource accessibility, or municipal structure; relationship among stakeholders, including homogeneity of community, influence of community leaders; and process, or the way things are done in the community. This contextualization of design and planning for the individual community or society, referred to as contextual engineering [12], is key to the development of sustainable infrastructure.

Contextual engineering is a predominantly qualitative process that recognizes the criticality of confronting community evaluator predispositions and biases, as well as acknowledging the existence of underlying relational and historical conditions that can affect nature of the interactions of system designers, the designed systems, and the community for whom these systems are built. In a simple way, it is a process that tries not only to understand the specific contexts of people and place, but tries to proactively use that knowledge to leverage context-specific system designs.

In the next section, an illustrative case study of a predominantly rural and remote population is described, including their issues with access to electricity, a program that has been developed to address it, and the challenges that remain. The program described in the case study is one wherein hybrid SHSs were identified as the type of DER system deemed most suitable for deployment to meet the needs of the population in question. This case study illustrates the importance 
of the contextual influences which require attention if progress is to be made on the use of DER systems for rural electrification.

\section{A Case Study: DER Systems in the Navajo Nation}

The Navajo Nation (NN) is the largest of the sovereign Native American territories, originally established as the Navajo Indian Reservation by the Navajo Treaty of 1868. It is located in the American Southwest, and at 27,413 square miles, is larger than the state of West Virginia. The total tribal membership of the $\mathrm{NN}$ is 331,813 , of which 173,667 resided within the NN territory as of the 2010 census [13] (a portion of the tribe lives on U.S. land). It is very sparsely populated, with a population density of approximately 6.3 persons per square mile. The low population density is reflective of the fact that the Navajo have traditionally been a herding society with strong ties to their ancestral land, and present day traditional Navajo choose to maintain the lifestyle of their ancestors [14]. In the past, families maintained large herds for which large tracts of grazing land were needed [14]. The NN is divided into five agencies (roughly equivalent to the county in the U.S. administrative sense): Western Agency, Chinle Agency, Fort Defiance Agency, Shiprock Agency, and Eastern Agency. These agencies are further subdivided into chapters (similar to municipalities), which are the smallest political unit. The seat of government is located in the capital city of Window Rock, in the St. Michaels chapter in Arizona. The modern three-part form of the NN government, comprising the judiciary, legislature, and executive, was established relatively recently, during the government restructuring of 1989. Prior to that, governance was conducted by a representative council and elected chairman which combined the functioning of legislative and executive, while judicial matters were handled by community elders through a mediation-style process. The members of the present legislative branch of government, the Navajo Nation Council, consists of 24 delegates chosen from the 110 chapters by direct election to serve for a period of 4 years [15].

The Navajo Tribal Utility Authority (NTUA) is the non-profit tribally-owned utility established as a service entity by the Navajo Tribal Government in 1959 to address the absence of utility services in the NN [14]. The NTUA strives to provide water, wastewater, gas, and electricity services to all residents of the NN to the best of its capabilities. Due to the low population density, last mile electrification remain a chronic problem in the NN. The sparse distribution of homesteads has meant that many homes are at least a mile from the nearest electrical distribution line, with some being up to 45 miles away [16]. The cost to electrify off-grid homes with line extensions ranges from approximately $\$ 35,000$ (single phase) to $\$ 60-80,000$ (three phase) per mile. These costs are deemed feasible only when there are more than eight houses per mile [17]. A low population density means that a significant portion of the population that does not live near transport thoroughfares and utility right-of-ways has no access to electricity from the grid. Recognizing the need of these customers, the NTUA provides them with the option of standalone DER systems. The current version of these standalone systems - developed in collaboration with Sandia National Laboratories' Solar Program is a skid-mounted solar photovoltaic (PV)-wind hybrid system. (Some PV-LPG hybrid systems are also provided to customers that need them; in this paper, the focus will be on the renewable-only DER systems). The NTUA has been investigating standalone DER systems for many years, having piloted the first generation of systems in 1993 [14]. The systems are provided to remote homes as a subscription-type service. A monthly subscription fee covers all parts and labor, and includes twice-yearly equipment inspections to make sure every component is performing within specifications. Panel incidence angles are also adjusted for summer and winter irradiation during these inspections. Previously, the systems were leased on a rent-to-own basis [18], but currently, they are provided on a leasing basis only [19]. The NTUA retains ownership of the system for the entire expected lifetime of the unit, and also takes responsibility for proper disposal of the unit at the end of the system's useful life. It is the largest off-grid residential PV program in the U.S. [20]. Indeed, as far as the authors are aware, it is the only such utility anywhere in the world which has such a long-standing DER systems provisioning and maintenance program focused on remote rural electricity service to make energy accessible to all customers within its service territory. Due to its role, the NTUA is more than simply a rural utility, instead being seen more as a vehicle for the NN's developmental policy, fulfilling a humanitarian role by servicing the needs of the Navajo people [14].

Because NTUA is a non-profit utility, capital investments for its service infrastructure have traditionally come from grants and other appropriations, as it cannot raise significant reserves through rate increases. The DER systems that the NTUA provides to its customers have been purchased through the years by means of grants and loans administered by various U.S. federal agencies. Table 1 shows how the DER program 
has evolved over the years, and the characteristics of the various system iterations that it has procured. To highlight the economic aspect of these systems for the customers, some simple Levelized Cost of Electricity (LCOE) and average price of electricity calculations can be performed. The LCOE is a convenient economic metric that describes the per-unit cost associated with energy generation of an energy project over its intended design life. The LCOE metric allows for a convenient comparison of the economic value of different types of energy sources or generation techniques. In particular, it has become a commonly used metric when arguing for the competitiveness of renewable energy resources. The LCOE metric is a simple computation, and is computed as:

$$
L C O E=\frac{\sum_{k=1}^{N} \frac{I_{k}+M_{k}+F_{k}}{(1+r)^{k}}}{\sum_{k=1}^{N} \frac{E_{k}}{(1+r)^{k}}} .
$$

Here, $I_{k}, M_{k}$, and $F_{k}$ are the annual investment, operation and maintenance (O\&M) cost, and fuel cost, respectively, for the $k$-th year (all in dollars), $E_{k}$ is the annual energy generated in the $k$-th year (in $\mathrm{kWh}$ ), $r$ is the discount rate, and $N$ is the expected service life of the system under consideration. Based on the system description and the terms of the NTUA maintenance contract, a first-order analysis can be performed by making the following observations regarding the cost and energy terms of the LCOE metric:

1. Under the subscription model adopted by NTUA, there is no annual investment required of the customer, so $I_{k}=0$ for all $k$.

2. As the monthly subscription fees are fixed at the time of contract initiation/system installation, the annual O\&M cost $M_{k}=M_{0}$ for all $k$.

3. As these systems are powered solely by renewable energy, the fuel cost $F_{k}=0$ for all $k$.

4. As the maintenance service includes replacement of components if their performance is outside of identified tolerances, we can assume that the annual energy produced by the system is constant over its lifetime, so $E_{k}=E_{0}$ for all $k$.

Under these operational paradigms, the LCOE computation simplifies as:

$$
\begin{aligned}
\text { LCOE } & =\frac{\sum_{k=1}^{N} \frac{M_{0}}{(1+r)^{k}}}{\sum_{k=1}^{N} \frac{E_{0}}{(1+r)^{k}}} \\
=\frac{M_{0}}{E_{0}} & \frac{\sum_{k=1}^{N} \frac{1}{(1+r)^{k}}}{\sum_{k=1}^{N} \frac{1}{(1+r)^{k}}} \\
& =\frac{M_{0}}{E_{0}} .
\end{aligned}
$$

In other words, the cost simply reduces to a measure of the average price of electricity paid by the customer. The computed LCOE will have units of $\$ / \mathrm{kWh}$, and it is worth noting here that the dollar value corresponds to the year of installation. For example, for a system installed in 2011, the appropriate units would be 2011 $\$ / \mathrm{kWh}$. To compare LCOE computations of systems installed across different years and generations, we can compute the corresponding future worth using a fixed baseline year, to which all values are referred. This can be done simply as:

$$
P=F(1+i)^{-n} .
$$

Here, $P$ denotes the present worth and $F$ denotes the future worth, and $i$ is the interest rate. In subsequent calculations, 2019 is used as the reference year, and all LCOE computations of the past years are referred to their future value for the year 2019. As such, $n$ is the difference between the year of system install and 2019. For the average price of electricity computations, the value obtained from (2) is used without correction for year of install.

\section{Results and Discussion}

The NTUA has had reasonable success with their program. Over the course of nearly 30 years, the DER program and the experience they have gained has been used as an example of a viable global model for rural electrification [17]. However, many problems still remain. Table 1 indicates that the NTUA has procured a total of 408 DER systems using the funds that were made available to it during the 30 years that the program has been operational. No information was available regarding how many houses were ultimately electrified with these systems or any repossessions which may have occurred due to non-payment of maintenance dues, if any. Funding obtained from the 2020 Coronavirus Aid, Relief, and Economic Security (CARES) Act also provided a means for the NTUA to procure an additional 300 DER systems for deployment [21]. The NTUA has also been connecting an average of 487 homes 
Table 1. Generations of DER Systems deployed by the NTUA [14] [16].

\begin{tabular}{|l|l|l|l|l|l|l|l|}
\hline Years & $\begin{array}{l}\text { Funding } \\
\text { Agency }\end{array}$ & $\begin{array}{l}\text { Amount } \\
\mathbf{( \$ )}\end{array}$ & $\begin{array}{l}\text { No. of } \\
\text { Units }\end{array}$ & $\begin{array}{l}\text { Array } \\
\text { Output (W) }\end{array}$ & $\begin{array}{l}\text { Array } \\
\text { Type }\end{array}$ & $\begin{array}{l}\text { Daily Energy } \\
\text { Generation (kWh) }\end{array}$ & $\begin{array}{l}\text { Monthly } \\
\text { Fee (\$) }\end{array}$ \\
\hline 1993 & DOE-WAPA & 350,000 & 40 & 260 & PV & 1.3 & 40 \\
\hline $1999-2001$ & USDA-RUS & $2,000,000$ & 200 & 640 & PV & 1.6 & 95 \\
\hline $2002-2003$ & $\begin{array}{l}\text { DOE-NEDP } \\
\text { (Phase I) }\end{array}$ & 800,000 & 40 & 880 & $\begin{array}{l}\text { PV-Wind } \\
\text { Hybrid }\end{array}$ & 2.0 & 75 \\
\hline $2003-2010$ & $\begin{array}{l}\text { DOE-NEDP } \\
\text { (Phase II) }\end{array}$ & $1,150,000$ & 63 & 880 & $\begin{array}{l}\text { PV-Wind } \\
\text { Hybrid }\end{array}$ & 2.0 & 75 \\
\hline $2010-$ Present & DOE & N/A & 65 & 1080 & $\begin{array}{l}\text { PV-Wind } \\
\text { Hybrid }\end{array}$ & 3.0 & 75 \\
\hline
\end{tabular}

DOE - WAPA : Department of Energy - Western American Power Administration,

USDA - RUS : United Stated Department of Agriculture - Rural Electricity Service,

DOE - NEDP : Department of Energy - Navajo Electrification Demonstration Program.

per year to the grid for the last 10 years under a separate electrification project, the Light Up Navajo Project [22]. Nonetheless, an estimated 15,000 off-grid homes, comprising approximately $30 \%$ of the total number of households in the NN, still remained to be electrified as of 2019 [23]. As such, even accounting for the grid electrification efforts and the DER systems at the NTUA's disposal, complete electrification remains a very distant milestone. In this section, some of the lingering challenges that remain in the use of these DER systems for affordable electrification are presented. Some of the pressing ones are technical challenges associated with maintenance, upkeep and customer education. The other set of challenges stem from the economic challenges that are a manifestation of historical and global drivers, and as such, are more deeply seated.

\subsection{Technical Challenges}

There are some lingering technical challenges with the DER systems that the NTUA has observed based on their accumulated experiences. One of the major causes of system failure has been reported to be due to premature battery failure [14]. On average, maintenance crews end up replacing system batteries every 5-7 years [17]. At least one report describes excessively low water levels in the flooded cell lead acid batteries as the largest cause of battery failures [14]. Service by maintenance crews involves topping of battery water levels with distilled water. They have also worked to train customers to monitor the battery water levels, and refill them when they fall too low.

Another major problem that contributes to premature battery failures has been due to over-discharge of the batteries. Excessive battery charge depletion results in the formation of irreversible crystallization on the electrodes of the battery. To counter this problem, newer systems have been designed with an automatic shut-off switch which takes the system offline if the battery depth-of-discharge (DOD) drops below a pre-set level, typically $10 \%$ [14]. To prevent customer frustration from such unforeseen outages, the NTUA installs an LED DOD meter in the customer's house and provides them with basic instruction on how to monitor the DOD levels of the system, and to reduce consumption temporarily when DOD levels are low. Customers of the current generation of the DER systems are also provided with energy efficient appliances (specifically, refrigerators) that are compatible with the capability of the DER systems to ensure they last for their intended service life. Vandalism has also been mentioned as a cause for concern. There have been instances where customers tried to open up the packaged system to remove the batteries for other uses, or tried to troubleshoot the systems themselves [14].

The challenges noted above are technical challenges, but understanding and developing potential solutions to these issues requires an understanding of the non-technical conditions of site and society. Depending on the resource availability of the society in question, some of the requirements may be onerous for customers. For example, for homesteads that are far from even the most basic of stores, distilled water is a resource in short supply. As a matter of fact, even general water access for human consumption remains a chronic problem in the NN. Armed with the knowledge of place-based contextual information, some design tweaks could be investigated to address these challenges, such as the use of maintenance-free sealed gel-type or AGM batteries, which do not require battery water level monitoring. Acts of vandalism or attempts to self-troubleshoot are also highly suggestive of the resource-constrained nature of the customers. Understanding these may be 
relevant in understanding appropriate design strategies for future iterations. If batteries are removed for other uses, such as to repair a vehicle that has broken down, it may be an indication of acute transportation issues, and the general lack of repair services in the community. Alleviating these resource-constrained considerations through other means may be necessary to prevent future instances of vandalism.

\subsection{Economic Challenges}

In contrast to the technical challenges described in the previous subsection, the challenges presented in this section are more related to the economically-constrained nature of the communities, and as such, do not necessarily admit purely technical solutions.

In Figures 1 and 2, some comparisons of the costs of energy obtained from the DER systems with that of trends at the U.S. national level are presented. The LCOE numbers for the national level are obtained from [24]. For the year 2019, the cost of electricity from

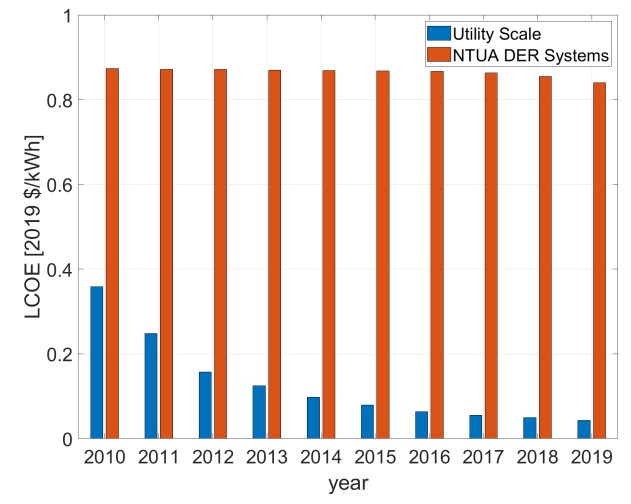

Figure 1. LCOE of the NTUA DER systems and utility-scale PV systems at the national level.

an NTUA DER system was about $82 \notin / \mathrm{kWh}$, compared to $4 \notin / \mathrm{kWh}$ at the utility scale level in the U.S. As such, electricity costs nearly 20 times more from these DER systems as compared to the bulk cost at the U.S. utility grid level. Even if prices paid by end-use residential customers are compared, it can be seen that a large disparity between the average end-use residential customers elsewhere in the U.S. and the NTUA DER system customer remains. From Figure 2, it can be seen that a NTUA DER system customer pays about $82 \phi / \mathrm{kWh}$, a price that is about six times higher than the average residential customer elsewhere in the U.S $(13 \notin / \mathrm{kWh})$. In comparison, NN customers who are connected to grid pay approximately $11.8 \notin / \mathrm{kWh}[26]$, about at par with a typical U.S. residential customer. One observation that can be made from Figures 1 and 2

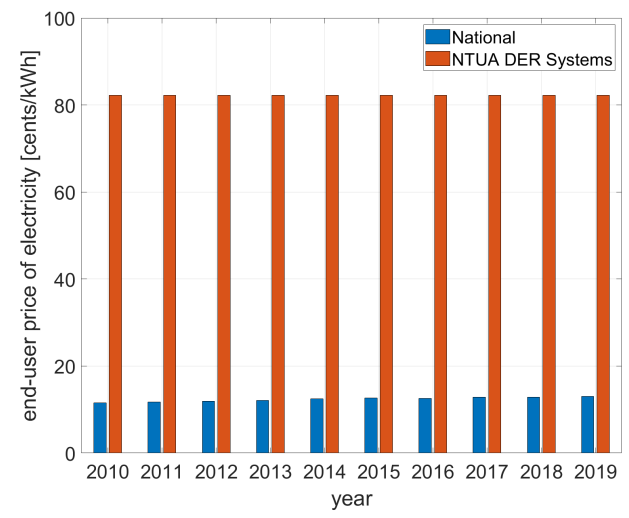

Figure 2. Average price paid for electricity by NTUA's DER system customers, as compared to the national average for end customers [25].

is that the DER systems are greatly affected by the lack of economies of scale (EOS). For these smaller systems, the O\&M forms a exceedingly large share of the cost, as maintenance and troubleshooting is manually-intensive, with no availability of remote online monitoring [20]. It is reported, in fact, that the NTUA does not end up recovering the cost of the DER systems over their lifetimes [17]. While there is no expectation to recover capital costs (given that the DER systems are procured using grants obtained from external agencies), maintenance expenses exceed the charges that the NTUA bills their customers. The payback calculations and the incomplete cost recovery indicates that the program in its current form is not self-sustaining, so its promise is limited. If this program model is adopted as a potential means of advancing off-grid rural electrification in similar situational contexts elsewhere, the high costs and low promise of capital recovery is likely to mean that it will not be as impactful as hoped.

The economic aspects of high per-unit energy costs are further exacerbated by the generally economically-disadvantaged nature of the customer base. Per the 2010 census, the per capita income in the $\mathrm{NN}$ was $\$ 10,695$, while the median household income was $\$ 27,389$. About $40 \%$ of the families live below the poverty level [13]. As such, the monthly subscription fee for the present generation of systems is not an insignificant portion of annual household income. Figure 3 shows how the household income distribution in the NN compares with the U.S. average. Evidenced by the median household income distribution in the $\mathrm{NN}$, the percentage of household income that customers who rely on the DER systems have to pay is often considerable. Figure 4 shows the minimum percentage of annual household income that a household has 


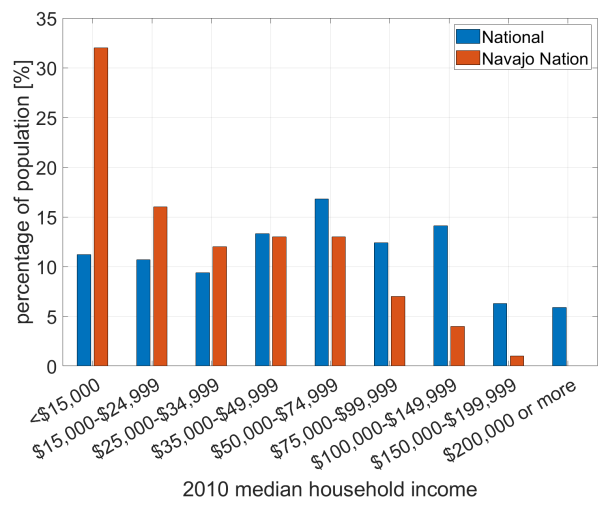

Figure 3. Household income distribution in the NN [13] as compared to the U.S. average [27].

to spend (based on the $\$ 75$ monthly charge) to be able to procure energy from these DER systems. For

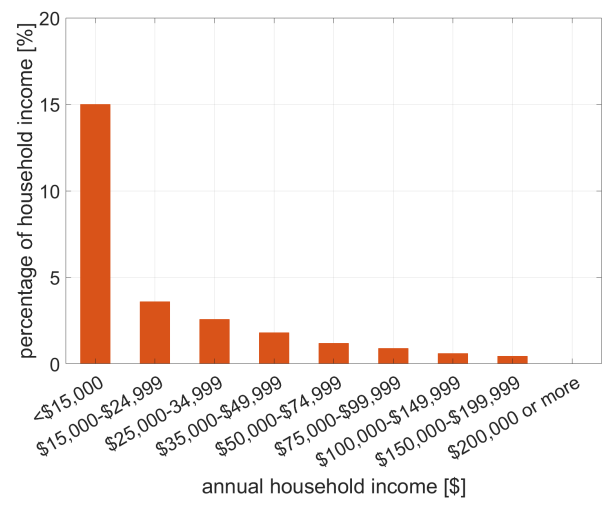

Figure 4. Minimum percentage of household income that a DER system customer has to spend on electricity access.

households with income less than $\$ 15,000$ (a group that comprises $32 \%$ of the population of the $\mathrm{NN}$, as seen in Figure 3), at least $15 \%$ of household income has to be allocated for electricity, if DER systems are their only option for electricity access. The general trends regarding income has also not been very optimistic in the NN, and does not seem to indicate that there will be much relief in the immediate future. Economic opportunity has been limited in the NN for decades, with the result that income has stagnated over the years, as seen in Figure 5. Data for the NN trend in the figure was only available up until 2016 , but it does serve to illustrate the general stagnation of median household income in the NN, especially compared to the U.S. national income trend.

At face value, these issues appear to be purely economic, but it must be emphasized that they stem

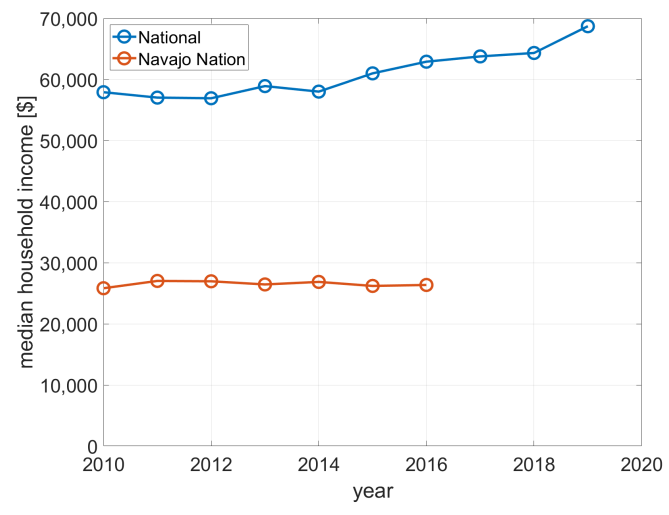

Figure 5. Trends in the median household income in the NN [28], compared to the U.S. national level [29].

from institutional factors that have been in motion over much longer time periods, and thus have significantly influenced the developmental trajectory on which NN communities find themselves today. Here is where the context-informing background of historical conditions and lived experiences of the Navajo people becomes particularly relevant. The Navajo have traditionally been a farming and herding community, with subsistence farming and sheep herding having been central to their cultural identity and economic capacity. However, a long series of forced assimilation pressures, beginning from the Long Walk of the Navajo in 1864 (where the Navajo population was temporarily forcibly displaced from their ancestral land; they returned later in 1868), followed by mandatory livestock reductions in the 1940s and later, has severely impacted their economic independence. Navajo households that previously managed herds comprising hundreds of animals were forced to limit their herds to 50 animals, a drastic reduction that destroyed their economic independence by crippling their major source of income.

The general income level of residents in the NN has also been affected by policies that have long-hindered meaningful development of economic activity. For much of its existence, the chief source of income in the $\mathrm{NN}$ has been through royalties obtained from mineral rights. These mineral leases were managed by the Bureau of Indian Affairs (BIA), with many leases being extremely unfavorable to the NN. As such, the resource exploitation has not helped the NN to significantly better their infrastructure. The forced assimilation policies of several successive U.S. Administrations that were in effect until very recently also attempted to force the Navajo out of their ancestral lands and encouraged them to migrate to cities elsewhere and assimilate with the rest of the country, leading to further disruptions 
to continuity in their living conditions. The Bennett Freeze, a development moratorium imposed by the BIA on certain Navajo lands, was another institutional policy decision that caused significant economic disruption. Put in place in 1966 ostensibly to promote negotiations and a settlement between the Navajo and Hopi Nations on the use of a tract of land called the Joint Use Area, it banned all development on 1.5 million acres (approximately 2,342 square miles) of the NN, covering nine chapters in the Western Agency. The development ban included construction and repair activities such as building houses, fixing roofs, commercial development, and constructing utility infrastructure. It lasted until 2009, when it was finally lifted [30]. Lasting over 40 years, it severely disrupted any economic development for an entire generation, and its effects are still being felt acutely today within those specific parts of the NN.

These policies have had the effect that, until very recently, there had been no concerted effort to develop infrastructure, a strong economy, and a labor force within the NN to deal with internal matters as a sovereign nation. Even in cases when opportunities are provided to help the Navajo develop businesses through loan programs, some cultural factors are not adequately accounted for. For example, one major issue faced by the NN and the U.S. government is the distinctiveness of land management practices: land in the NN is held in trust and communally owned. Families are granted rights to land for farming and grazing, which may be passed down through generations, but not owned outright. The concept of titles and exclusive ownership is not traditional. This means that prospective Navajo entrepreneurs are unable to provide conventional documents such as land titles as collateral to obtain loan financing. The global and local factors that result in the present situation remain, and as such, long-term policy, adapted for the specific contexts of place and people, needs to be developed to address these. Barring long-term road maps laid out through long-term policy initiatives, the promise to expand electrification using DER systems may need to be tempered.

\section{Conclusion and Future Work}

In this paper, the Navajo Nation was used as an illustrative case study and their challenges using DER systems for rural electrification were described. Some of the challenges that are relevant in their specific context were described. Nonetheless, it can be seen upon some reflection that the issues that they are confronting are also broadly applicable for similar settings in different regions of the world.

The general focus here was on rural remote communities with under-developed energy resources. In that regard, it is hoped that that this paper has been able to impress upon the reader that contextual factors of people and place are unique to every community, that lived experiences define how these communities interact with technology, and that holistic and long-term contextualized policy is required to ultimately address the energy poverty of these communities.

From a technology vs. policy perspective then, it is incumbent upon us to reflect that technology solutions can only alleviate a relatively small set of challenges that are likely to be encountered in the quest to reduce energy poverty using DER systems. Achieving long-lasting success requires adopting a similarly long-term view of all contributing factors and attempt to address those satisfactorily as well. As a variety of factors leads a distinct community to find themselves in their present energy poverty predicament, it is too simplistic to harbor the notion that advances in technology alone will be able to alleviate it. It must be recognized that uniqueness of culture, historical events, and global drivers have shaped the present of communities in ways that ultimately define the scope within which they interact with technology, as well as their capability to afford technology. Energy poverty reduction therefore requires a multi-pronged approach, including, but not limited to, development of indigenous skills, improved accessibility, communication, etc.

Future work for this project involves field visits and ethnographic data collection to better develop an understanding of the community constraints based on cultural, political, economic, and educational influences. Some preliminary work on the process of incorporating contextual influences into the design process - albeit for a different community - has been presented in [31]. Knowledge of these influences can help in developing general frameworks that can be used to develop targeted technical and policy solutions for communities.

\section{References}

[1] R. Day, G. Walker, and N. Simcock, "Conceptualizing energy use and energy poverty using a capabilities framework," Energy Policy, vol. 93, pp. 255-264, 2016.

[2] L. E. Armey and L. Hosman, "The centrality of electricity to ICT use in low-income countries," Telecommunications Policy, vol. 40, no. 7, pp. 617-627, 2016.

[3] C. Kirubi, A. Jacobson, D. M. Kammen, and A. Mills, "Community-based electric micro-grids can contribute to rural development: Evidence from Kenya," World Development, vol. 37, no. 7, pp. 1208-1221, 2009.

[4] O. Edenhofer, et. al, ed., IPCC Special Report on Renewable Energy Sources and Climate Change Mitigation, ch. IPCC, 2011: Summary for Policymakers. Cambridge University Press, 2011. 
[5] S. Feron, "Sustainability of off-grid photovoltaic systems for rural electrification in developing countries: A review," Sustainability, vol. 8, pp. 1-26, 2016.

[6] H. J. Corsair, Causes of success and failure of stand-alone solar electric systems in rural Guatemala. $\mathrm{PhD}$ thesis, Johns Hopkins University, 2013.

[7] V. Gómez García and M. M. Bartolomé, "Rural electrification systems based on renewable energy: The social dimensions of an innovative technology," Technology in Society, vol. 32, no. 7, pp. 303-311, 2010.

[8] A.-P. Witmer, "The influence of development objectives and local context upon international service engineering infrastructure design," International Journal of Technology Management and Sustainable Development, vol. 17, no. 2, pp. 135-150, 2018.

[9] A. Arshad-Ayaz, M. A. Naseem, and D. Mohamed, "Engineering and humanitarian intervention: Learning from failure," Journal of International Humanitarian Action, vol. 5, no. 7, pp. 2-14, 2020.

[10] A. Chatterjee, D. Burmester, A. Brent, and R. Rayudu, "Research insights and knowledge headways for developing remote, off-grid microgrids in developing countries," Energies, vol. 12, no. 10, pp. 1-19, 2019.

[11] D. Akinyele, J. Belikov, and Y. Levron, "Challenges of microgrids in remote communities: A STEEP model application," Energies, vol. 11, no. 2, pp. 1-35, 2018.

[12] A.-P. Witmer, "An ethnographic justification for establishment of a contextual engineering discipline," Journal of Engineering Design and Technology, vol. 18, no. 2, pp. 389-413, 2019.

[13] Arizona Rural Policy Institute, "Demographic analysis of the Navajo Nation," Report, Northern Arizona University, 2010.

[14] J. Coots, "A decade of changes to an alternative power source for a rural utility," Technical Report SAND 2004-5102P, Sandia National Laboratories, October 2004.

[15] "The Navajo Nation Profile." https://navajopr ofile.wind.enavajo.org/NavajoNation/. [Online; accessed 30-May-2021].

[16] N. Y. Cata, "Sustainable rural electrification: Residential solar energy on the Navajo Nation," Technical Report SAND 2013-4172P, Sandia National Laboratories, 2012.

[17] S. K. Begay, "Navajo residential solar energy access as a global model," Electricity Journal, vol. 31, September 2018.

[18] WHPacific Inc., "Bodaway Gap Comprehensive Land Usage Plan (CLUP)." http://www.bodaway.na vajochapters.org/12-23-08-bodaway-cl up.pdf, 2008. [Online; accessed 25-April-2021].

[19] Navajo Tribal Utility Authority, "NTUA solar photovoltaic service." https: / / www. ntua.c om/renewable-energy.html. [Online; accessed 25-May-2021].

[20] T. Battiest, "Navajo Tribal Utility Authority program system data and O\&M initiative for DOE solar technologies database," Technical Report SAND 2010-7617P, Sandia National Laboratories, December 2007.

[21] Navajo Tribal Utility Authority, "CARES Act: NTUA's Off-Grid Solar Program." https : / / www. ntua.c om/caresactsolar.html. [Online; accessed 20-August-2021]
[22] American Public Power Association, "Lighting the Navajo Nation." lhttps: / / www.publi cpower. org/periodical/article/lighting-nava jo-nation. [Online; accessed 20-August-2021].

[23] M. Gallucci, "The Land Electrification Forgot," IEEE Spectrum, May 2019. [Online; accessed 20-August-2021].

[24] Lazard Ltd., "Lazard's levelized cost of energy analysis - Version 13.0." https: / / www. lazard.com/med ia/451086/lazards-levelized-cost-ofenergy- \\version-130-vf.pdf, November 2019. [Online; accessed 30-May-2021].

[25] U.S. Energy Information Administration, via Statista, "Average retail price of electricity to the residential sector in the United States, 1975-2020." https : / / ww w.statista.com/statistics/200199/res idential-sector-electricity-prices-i n-the-us-since-1975/, April 2021. [Online; accessed 26-April-2021].

[26] Navajo Tribal Utility Authority, "NTUA regional utility rates comparison." https: / / www. ntua.com/ass ets/regional-utility-rates-2021.jpg. [Online; accessed 30-May-2021].

[27] U.S. Census Bureau, via Statista, "Percentage distribution of household income in the United States from 2006 to 2019." https : / / www . statista.com /statistics/758502/percentage-distri bution-of-household-income-in-the-us /, September 2020. [Online; accessed 03-June-2021].

[28] Navajo Nation WIND, from American Community Survey (ACS) 5-years estimate, "Profile of Selected Economic Characteristics." https: / / navajoprof ile.wind.enavajo.org/\#, September 2020. [Online; accessed 03-June-2021].

[29] U.S. Census Bureau, via Federal Reserve Bank of St. Louis, "Real Median Household Income in the United States." https: / / fred.stlouisfed.org/se ries/MEHOINUSA 672N, September 2020. [Online; accessed 03-June-2021].

[30] Navajo Thaw Implementation Plan, "About the Bennett Freeze." https: / / navajothaw.com/about -the-bennett-freeze/. [Online; accessed 20-August-2021].

[31] A. Chattopadhyay, A.-P. Witmer, and P. W. Sauer, "The need for teaching place-based contextualization for sustainable power system infrastructure design," IEEE Transactions on Power Systems, April 2021. [Online], Available doi: 10.1109/TPWRS.2021.3072069. 